\title{
SIMULATION AND ANALYSIS OF
}

\section{COMPACT REMOTE MONITORING}

\section{SYSTEM}

\author{
Sachin Kumar B S ${ }^{1}$, Dr.NageshPrabhu ${ }^{2}$ \\ PG Scholar, NMAMIT, Nitte, India \\ Professor \& Head, Department of E\&E, NMAMIT, Nitte, India ${ }^{2}$
}

\begin{abstract}
Remote Monitoring System is one of the fast developing technologies, used for many industrial as well as domestic applications. This project proposes a compact design and development of remote monitoring system for a three-phase generator. Arduino microcontroller and ZigBee based Wireless devices are used for monitoring the operating point of three phase generator remotely. The Arduino microcontroller helps in monitoring the three phase current, voltage, temperature and power of the generator. The ZigBee-based wireless device is used as a wireless communication between the transmitter and receiver modules. The processed parameters are displayed on 20x4 line Liquid Crystal Display(LCD) which makes the system user friendly. An alert system is enabled through Arduino microcontroller if the load current is more than the full load capacity of the generator.
\end{abstract}

Keywords: Remote monitoring, Arduino, ZigBee, 20x4 LCD.

\section{INTRODUCTION}

Remote monitoring for various devices is already been implemented using several techniques[1]-[6]. In industrial applications monitoring is carried out mostly on parameters such as voltage, current, power, temperature [1]-[5]. In case of domestic applications parameters such as humidity level, temperature, gasleakage [6] are monitored by interfacing several sensors with the controller. In the present work, remote monitoring ofa three phase generator is implemented. Healthy operation of the generator can be ensured by monitoring the real time data from a remote location. ZigBee is the mode of wireless communication between generator end and the monitoring end. At the generator end,Measured parameters are displayed on a 20x4 LCD and same parameters are transmitted through ZigBee. At the monitoring end, parameters are received through ZigBee, processed through Arduino and displayed on 20x4 LCD.

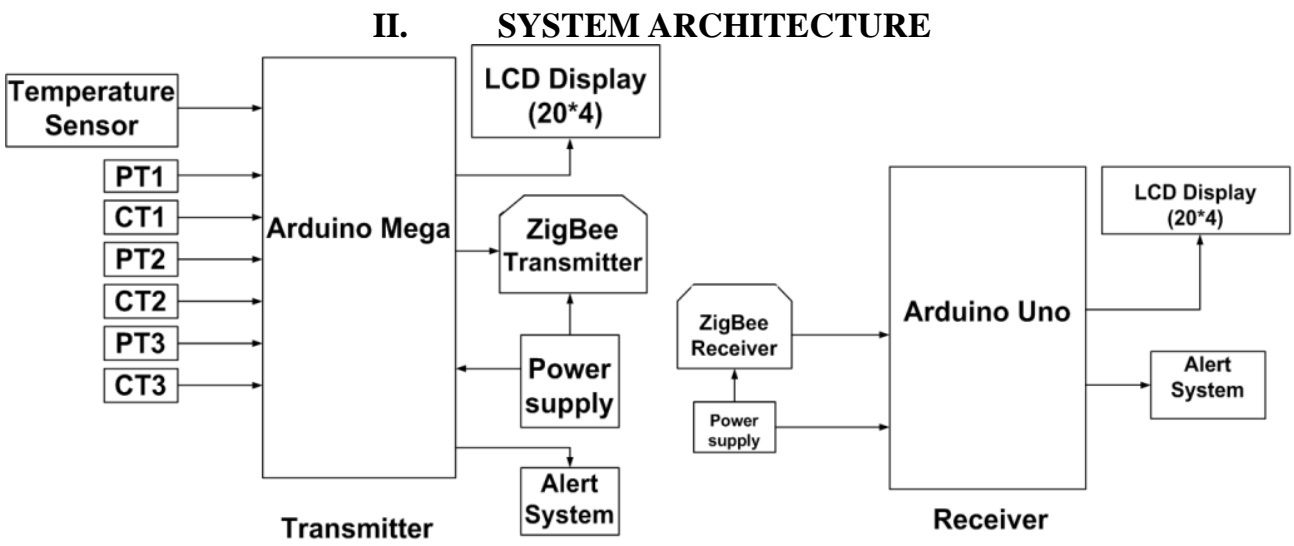

Fig.1. Transmitter and Receiver Architecture of the Monitoring System

The architecture of the transmitter and receiver embedded system is shown in Fig.1. The parameters of the generator like temperature, current fluctuations and voltage fluctuationsare monitored remotely through ZigBee network. The sensors sense the changein temperature, current and voltage levels and send the signal to the microcontroller. Analog values are taken from the sensors to an Arduino through an inbuilt ADC. The Arduino that is powered by a power 
supply sends the signal to a Zig Bee transmitter. The ZigBee transmitter transmits the data through wireless communication ata baud rate of 9600 bytes per second. This data i.e. the values of the temperature, current and voltage levels of the generator are displayed on the LCD and received by the ZigBee receiver module (co-ordinating module) at the same baud rate, with both the ZigBee modules kept apart at a maximum distance of 100 metres. The value which is received is displayed on 20x4 LCD. Thus, the data is received at both the ends, i.e. transmitter as well as the receiver end. At the same time, the Arduino checks whether the levels of temperature, current and voltage are above or within the generator rating. Alert pin of the Arduino is activated if load current is more than the generator capacity,and causes LED to glow, Buzzer will generate beep and causes tripping of the generator.

\section{SYSTEM DESIGN}

The embedded system is the combination of sensors, Arduino microcontroller and a ZigBee module. Sensors are used to acquire data from the generator. Transformer will step down the voltage which is fed to voltage sensor. Load will draw a maximum of $30 \mathrm{~A}$ current which is measured by the ACS712,30A current sensor. Voltage sensor connected across the load will measure the voltage as shown in Fig.2. Digital temperature sensor (DS18S20) is used to monitor the temperature. These measured parameters are processed by Arduino Mega and displayed on a 20x4 LCD. The same parameters are also transmitted through ZigBee module.

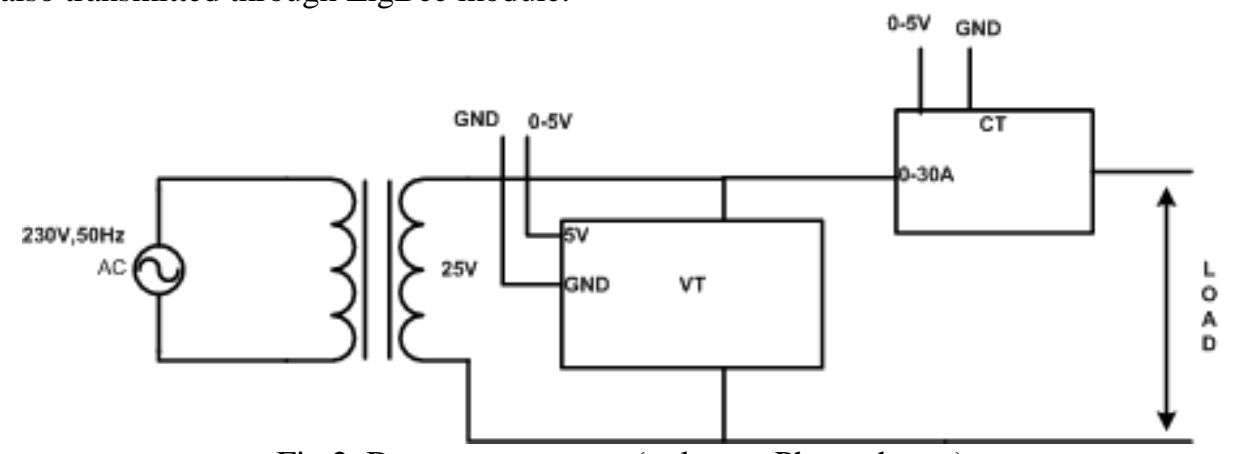

Fig.2. Data measurement (only one Phase shown)

At the remote end the receiver ZigBeewill receive the parameters and the Arduino Uno microcontroller will process these data and display the parameters on 20x4 LCD attached to it. Alert signal is generated at transmitter as well as receiver end if the load current of the generator is more than the full load capacity of the generator.

\section{FLOW DIAGRAM}

Fig.3. shows the flowchart of the transmitter and receiver end Arduino microcontroller. At the transmitter side, once the Arduino is powered up, it initializes the LCD and collects data from all the sensors. The collected data are processes and displayed on the LCD attached to it. Arduino also transmits these data through ZigBee module. At the receiver side, these data are received by the ZigBee module and given to receiver pin of Arduino. Arduino will process these data and display on 20x4 LCD attached to it. An alert signal is generated at transmitter as well as receiver end if the load current of the generator exceeds the full load capacity of the generator.
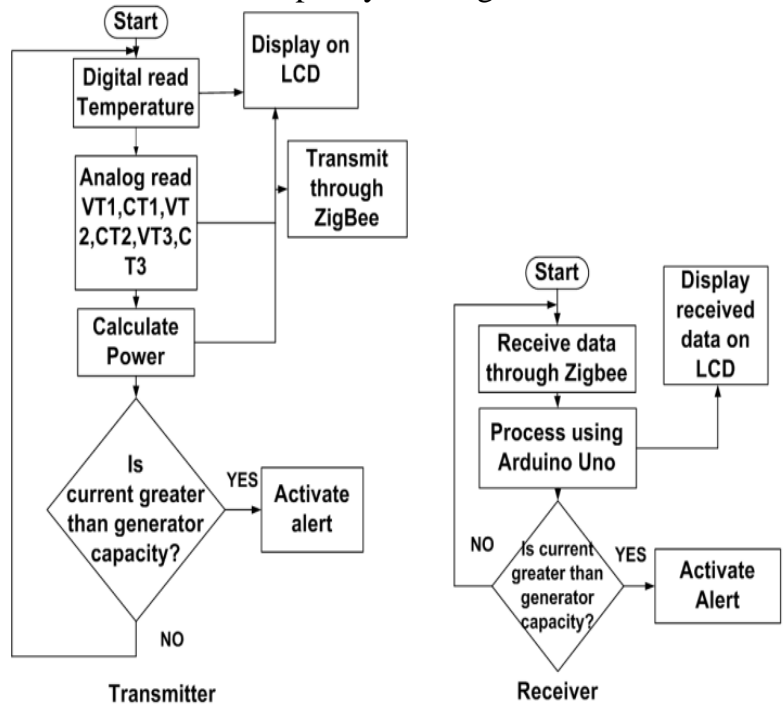
Fig.3.Flowchart of Transmitter and Receiver

V.

SIMULATION AND RESULT

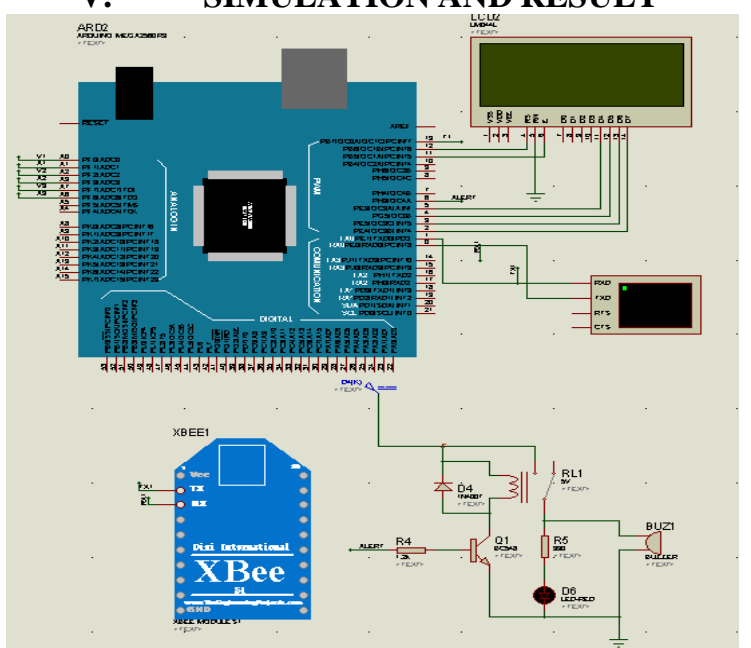

Fig.4. Transmitter side simulation model

Simulation of the study system is carried out in Proteus 8.1. Voltage sensor, current sensor (ACS712,30A), temperature sensor model (DS18S20) are connected to Arduino mega microcontroller to obtain the parameters such as voltage, load current and temperature of the generator as shown in Fig.4. Voltage and current sensors are connected to analog pins of Arduino mega. Voltage sensor reads the voltages and produces the output in $0-5 \mathrm{~V}$ range. $10 \mathrm{bit}$ ADC is used to convert the voltage and current back with high resolution. Current sensor reads 0-30A current and produces the output in the range of $0-5 \mathrm{~V}$.Temperature sensor is connected to digital pin of Arduino since it gives out digital data. These parameters are processed through Arduino and displayed on LCD and Virtual terminal. Then these parameters are transmitted through ZigBee module as shown in Fig.4. Alert system consists of a relay which is switched to turn on the LED and buzzer in case of over load situation. Alert pin of the Arduino turns high when the load current increases above the full load capacity of the generator.

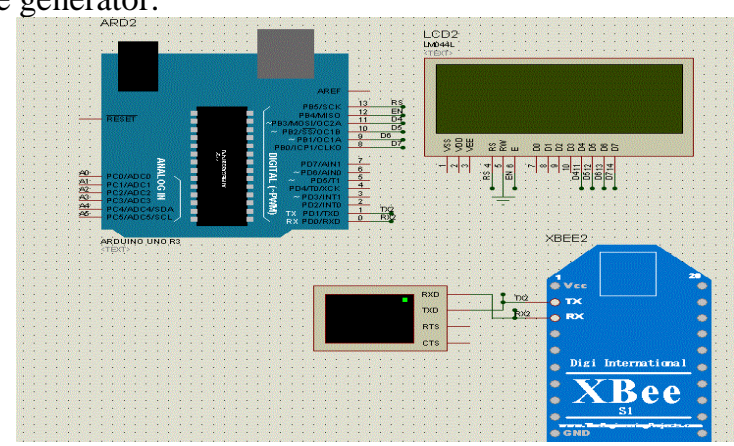

Fig.5. Receiver side simulation model

ZigBee receiver is connected to the Tx and Rx pin of the arduino as shown inFig. 4 and Fig.5. Data received by the ZigBee is processed through Arduinouno and displayed on 20x4 LCD. Fig. 6 shows the simulation result of the transmitter side. Measured parameters such as voltage, current, power and temperature of the generator are displayed on 20x4 LCD as well as in virtual Terminal.Each phase parameters are displayed in separate column on LCD. Same parameters are transmitted through ZigBee every 5 second.

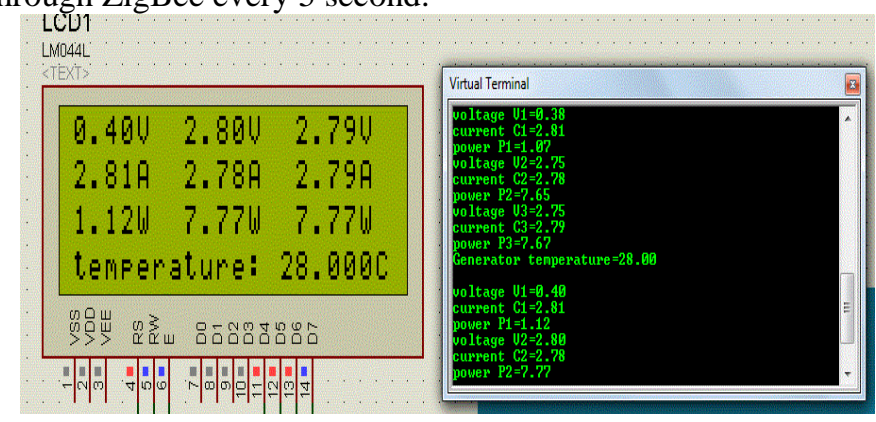


Fig.6. Transmitter end simulation result

At the receiver end, ZigBee will receive the parameters which further processed by Arduino Uno as shown in Fig. 5 and displayed on LCD and virtual terminal as shown in Fig.7. This enables the operator to read the generator parameters from a remote location.

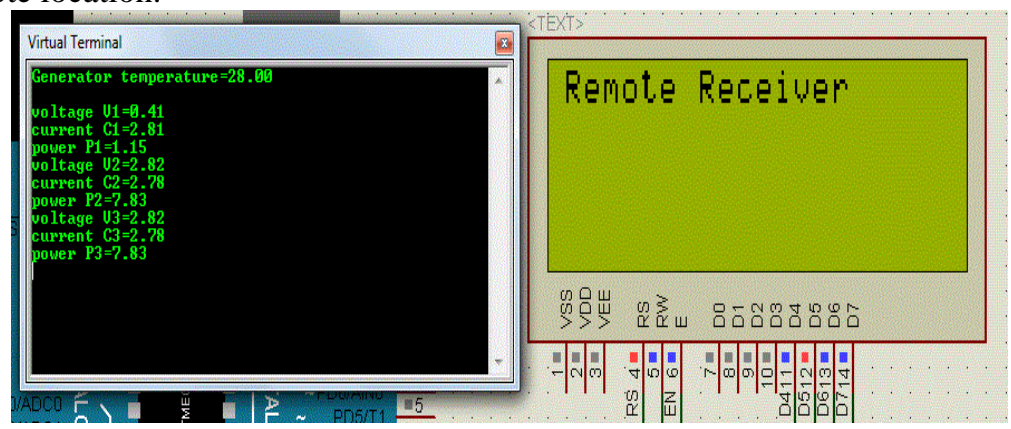

Fig.7. Receiver end simulation result

\section{CONCLUSION}

The Remote Monitoring system designed helps in monitoring the three phase parameters of the generator. Monitoring can be carried from a remote location. This reduces the time and man power requirement. Display is provided at both transmitter and receiver end which makes the system user friendly. All sensors required to monitor 3 phase parameters are processed bysingle microcontroller, which makes the system compact.

\section{ACKNOWLEDGMENT}

The authors acknowledge the financial support received under the TRIP Programme of VGST Bangalore and express deepest gratitude to NMAMIT Nitte \& Visvesvaraya Technological Universityfor all the encouragement and support.

\section{REFERENCES}

[1]. HariAriefDharmawan and Sam A. M. Ali, "A Compact Remote Monitoring System for a Three-Phase 10-kVA Energy-Efficient Switchable Distribution Transformer” IEEE TRANSACTIONS ON INSTRUMENTATION AND MEASUREMENT, VOL. 61, NO. 3, MARCH 2012

[2]. BiswenduChatterjee, DebangshuDey, Member, IEEE, and SivajiChakravorti, Senior Member, IEEE, "Implementation of an Integrated, Portable Transformer Condition Monitoring Instrument in the Classroom and On-Site" IEEE TRANSACTIONS ON EDUCATION, VOL. 53, NO. 3, AUGUST 2010

[3]. Donald Chu, Chairman, Andre Lux, Secretary, "On-Line Monitoring of Power Transformers and Components: A Review of Key Parameters" IEEE TRANSFORMER ON-LINE MONITORING TASK FORCE

[4]. C. Shiny Jennifer, B.V. Baiju, K. Anusree, "Monitoring Factory Machine Status from Remote Location using GSM Technologies" C. Shiny Jennifer et al, INTERNATIONAL JOURNAL OF COMPUTER SCIENCE AND MOBILE COMPUTING, Vol.3 Issue.2, February- 2014, pg. 343-352

[5]. V.RukkumaniD.AngelineVijulaS.Allirani Sri Ramakrishna Engineering College , Coimbatore, India, "Multiple parameter Monitor and Control in Wind Mills" INTERNATIONAL JOURNAL OF COMPUTER APPLICATIONS AND TECHNOLOGY (2278 - 8298) Volume 1 - No. 1, 2012, 40-43

[6]. VaneetSinghi, Guru TeghBahadur Institute of Technology New Delhi, India, I. P. Singh, s. K. Sud, Indian Institute of Technology Delhi, New Delhi, India, "Environment monitoring and device control using ARM based Embedded Controlled Sensor Network"978-1-4673-53014/13/\$31.00 (C2013 IEEE

\section{BIOGRAPHIES}

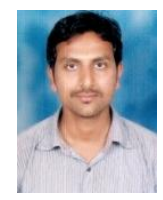

Sachin Kumar B S, received her B.E. (E\&C) degree from St.Joseph Engineering Collage, India in 2011. Pursuing M.Tech.(Microelectronics and Control Systems) in NitteMahalingaAdyanthaya Memorial Institute of Technology, Nitte, Karkala, India. His area of interest includes DC Machines and Embedded systems.

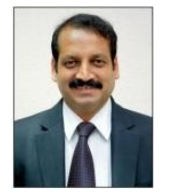

NageshPrabhu received the Dipl. Elect. Eng. Degree from Karnataka Polytechnic, Mangalore, India, in 1986, M.Tech. degree in power and energy systems from Karnataka Regional Engineering College Surathkal, India (presently N.I.T. Karnataka) in 1995, and the Ph.D. degree from the Indian Institute of Science, Bangalore, in 2005.Currently, he is Professor and Head of Electrical and Electronics Engineering at NMAM Institute of Technology, Nitte, India. He has served in the academic field since 1986. His research interests are in the area of power system dynamics and control, HVDC and FACTS, and custom power controllers. Dr.Prabhu is a life member of the Indian Society for Technical Education and Indian Society of Lighting Engineers. 